\title{
Use of a Video Module to Improve Faculty Understanding of the Pharmacists' Patient Care Process
}

Crystal M. Deas, PharmD, BCPS; Angela R. Thomason, PharmD, BCPS; Robert M. Riggs, PhD, RPh;

Michael C. Thomas, PharmD, BCPS, FCCP; Michael G. Kendrach, PharmD, FASHP

Samford University, McWhorter School of Pharmacy

\begin{abstract}
Objective: To evaluate change in faculty's knowledge and perceptions after an online video module on the Pharmacists' Patient Care Process (PPCP).

Innovation: An educational video module on the PPCP was developed and disseminated to full-time faculty members at Samford University, McWhorter School of Pharmacy. Voluntary and anonymous pre- and post-test assessments were evaluated and analyzed.

Critical Analysis: Thirty faculty completed the pre-assessment, and 31 completed the post-assessment (73\% and $75 \%$ response rates, respectively). A significant improvement in faculty perceptions was indicated by an increase in agreement with the majority (80\%) of questions on attitudes toward the PPCP on the post-test. Faculty's knowledge of the introduction and assessment of PPCP within the school's curriculum was significantly increased after viewing the video module. After viewing the module, more faculty were also able to correctly identify the majority of the PPCP components and their corresponding practice activities.

Next Steps: A short video module was effective at improving faculty knowledge and perceptions of the PPCP. Development of a similar faculty development module is feasible for implementation in other Schools of Pharmacy.
\end{abstract}

Keywords: Pharmacists' Patient Care Process, faculty development, video

\section{Introduction}

Pharmacists are uniquely positioned within the healthcare system to identify medication-therapy problems and improve patients' health outcomes. As a profession, the work of Hepler and Strand on the pharmaceutical care model, which promotes pharmacists as engaged members of healthcare teams and active partners in the design, implementation, and monitoring of drug therapy plans, has been taught and practiced for over 20 years. ${ }^{1-5}$ However, the methodology of this approach to patient care is variable among the profession and in pharmacy education; the need for a standardized process was recognized and addressed in the 2014 Joint Commission of Pharmacy Practitioners' (JCPP) report. ${ }^{6-7}$

The Pharmacists' Patient Care Process (PPCP) is a consensusbased, patient-centered approach to care that was developed and approved by the JCPP to provide a systematic pharmacist care delivery model across various practice settings. ${ }^{6-8}$ The patient is present in the center of the process, with the core activities of pharmacists' collaboration and communication with various stakeholders and documentation of care providing the foundation of the PPCP. ${ }^{6}$ The process itself involves five continuous steps: collection of pertinent patient information, assessment of collected data, development of an individualized, patient-centered treatment plan, implementation of the plan, and monitoring and evaluation of the plan and patient to achieve desired therapeutic outcomes. $^{6-7}$

Corresponding author: Crystal M. Deas, PharmD, BCPS

800 Lakeshore Drive, Birmingham, AL 35229

Phone: 205-726-4079; Email: cdeas@samford.edu
The PPCP has since been incorporated into the 2016 Accreditation Council for Pharmacy Education Standards for the Doctor of Pharmacy curriculum in an effort to ensure that PPCP is consistently taught to student pharmacists. ${ }^{7-8}$ The adoption of a uniform approach to patient care for pharmacists is supported by numerous national organizations and schools of pharmacy, given the potential for this methodology to advance the profession - namely in the areas of provider status and reimbursement. ${ }^{6-8}$

\section{Statement of Innovation}

During the fall 2016 semester, a PPCP Faculty Group (PPCPFG), comprised of members from various roles within the school (Associate Dean of Academic Affairs, Chair of Pharmacy Practice, Experiential Assistant Director, and PPCP faculty champions), was established at Samford University McWhorter School of Pharmacy. The PPCP-FG was charged with outlining the PPCP within the curriculum (didactic and experiential) and dissemination of information to faculty. The faculty group used the Pharmacists' Patient Care Process SelfAssessment $\mathrm{Tool}^{9}$ to locate and map out PPCP within the curriculum, didactic or experiential, based on year taught, course number, type of activity, type of instruction, and type of assessment including Bloom's taxonomy based on documents and information submitted by faculty. The group developed an innovative 22-minute video module, which included the PPCP definition, a practice application of the PPCP and information on the introduction and assessment of the PPCP in the Doctor of Pharmacy curriculum (Table 1). The video module design was selected by the group over other methods, based on positive outcomes with instructional use of video. ${ }^{10}$ The objective of this project was to evaluate change in 
faculty's knowledge and perceptions after an online, educational video module on the PPCP.

A pre-and post-survey was utilized to evaluate the change in School of Pharmacy faculty's knowledge and perceptions of the PPCP after viewing the video module. The video was created using the green screen technology of TouchCast Studio ${ }^{\circledR}$ (TouchCast ${ }^{\circledR}$ Version 1.17.1, New York, NY) application for iPad $^{\circledR}\left(\right.$ Apple $^{\circledR}$, Cupertino, CA) in conjunction with the TouchCast Remote ${ }^{\circledR}$ (TouchCast ${ }^{\circledR}$ Version 1.3, New York, NY)

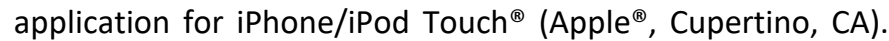
Video editing was performed using Camtasia 2 for $\mathrm{Mac}^{\circledR}$ (version 2.10.5, Techsmith $^{\circledR}$, Okemos, MI).

The survey instrument was developed by the School of Pharmacy's PPCP-FG, which was comprised of faculty with experience in survey methodology from both the department of Pharmacy Practice and the Pharmaceutical, Social and Administrative Sciences. The survey instrument consisted of two domains (perceptions and knowledge), totaling 10 questions. A five-point Likert scale was used to quantitatively assess five items on the survey ( $5=$ Strongly Agree and $1=$ Strongly Disagree) related to PPCP perceptions. The second domain of the instrument was comprised of five questions, such as multiple choice and matching, that evaluated faculty's knowledge of the origin of the PPCP, the order of the elements of the PPCP, pharmacist's tasks that correspond with the PPCP elements during a patient encounter, and the level of PPCP teaching within the required curriculum.

All full-time faculty of Samford University McWhorter School of Pharmacy were invited via email to participate before and after the release of the video module. The anonymous and voluntary electronic pre-survey was distributed to all School faculty in December 2016 using Qualtrics (Qualtrics, LLC, Provo, UT). The invitation included the purpose of the video, plus the link to the online pre-survey assessment. The assessment could be taken from any computer with Internet access and was available at any time during a 21-day period. At the closing date of the pre-assessment, in January 2017, the workgroup launched the video module and post-assessment through email distribution. The video and post-assessment questionnaire were accessible for three weeks. The postassessment questionnaire was embedded at the end of the video, which required participants to watch the video before accessing it. The pre- and post-assessment were the same survey instrument. Emailed reminders were sent to maximize participation. This study was approved by the Samford University Institutional Review Board.

Analysis of pre- and post-activity knowledge test scores were conducted using Fischer's exact test, independent t-test, and Welch's t-test, based on subdomain characteristics. MannWhitney test was used to detect differences in analysis of
Likert scale data. An alpha value of $p<.05$ was considered significant. Statistical analyses were conducted using SPSS (IBM Corp. Released 2015. IBM SPSS Statistics for Windows, Version 23.0. Armonk, NY: IBM Corp).

\section{Critical Analysis}

A total of 41 full-time faculty were invited to participate in the pre- and post-surveys; 30 and 31 faculty members completed the pre- and post-surveys (73\% and $75 \%$ response rate), respectively. A significant change in faculty perceptions of selfperceptions of their knowledge of PPCP was noted as a shift from $17 \%$ strongly disagree/disagree in the pre-survey to a post-survey percentage of $100 \%$ agree/strongly agree. A similar shift in agreement was observed in the item assessing faculty perceptions of the role of the PPCP in improving patient health outcomes and reducing medication errors. A nonsignificant change was observed in faculty perceptions of the pharmacy professions' knowledge of PPCP and need for inclusion of PPCP within the curriculum (Table 2).

In the knowledge questions, a large percentage of faculty (>90\%) correctly placed the elements of the PPCP process in both the pre-survey and post-survey. For subdomains (correct matching of the practice activity with the corresponding element of the PPCP process), the results show a significant shift from incorrect responses in the pre-survey to correct responses in the post-survey (Figure 1). The faculty in the presurvey and post-survey had a $100 \%$ correct response rate in identifying the JCPP as the adopting body of the PPCP. In the pre-survey, the respondents correctly identified $58.9 \%$ of the courses that introduced PPCP in the curriculum. In the postsurvey, the percentage increased to $71.1 \%(p=.088)$. When faculty were asked to identify the courses where mastery of the PPCP process was assessed in the curriculum, $63.3 \%$ identified them correctly in the pre-survey and $87.5 \%$ in the post-survey $(p=.002)$.

This study assessed the use of online video modules to enhance faculty professional development related to the PPCP. While the steps of the PPCP have been practiced in the pharmacy profession, a consistent nomenclature for the process has not been utilized until the adoption of PPCP by JCPP. Pharmacy faculty are at the forefront of influencing the immediacy and depth of real-world implementation of PPCP into practice. Therefore, faculty development on the process is paramount and should occur on a consistent basis. In addition, use of a PPCP video module is an approach that may also be useful in education and introduction of the PPCP to pharmacy students, school/college of pharmacy staff, external preceptors, and other healthcare providers.

In this study, the use of an online video module had a positive impact on the School's faculty perceptions and knowledge related to PPCP. The module was available and completed by 
both pharmacy practice and pharmaceutical, social, and administrative science faculty. The majority of faculty's perceptions improved, as it related to their own knowledge, as well as perceived importance of PPCP implementation on patient outcomes and medication errors. This positive response from faculty is important as personal endorsement of the process promotes a shared philosophy, across departments, of the core elements of pharmacist-provided patient care. In addition, faculty's perceptions of the positive impact of the process on patient health outcomes could encourage consistent teaching of PPCP across the curriculum - in both pharmacy practice and basic science courses.

A non-significant shift in agreement was observed in faculty perceptions regarding the importance of teaching PPCP to students. However, high faculty agreement was present with this assessment item at baseline. Overall, faculty perceptions of the pharmacy profession's collective knowledge of PPCP was poor in the pre-survey and improved slightly after the online module $(p=.12)$, which is suggestive of the need for continued education. Faculty represent one key element for implementation of PPCP, but they alone cannot promote the widespread application of the process in practice. Consistent implementation of PPCP will depend of the uniform endorsement of various stakeholders and agreement that the process describes the most basic and non-negotiable elements of pharmacist-provided patient care. The use of uniform messaging with various educational tools, such as online video modules, may be a helpful in initial interventions to engage these stakeholders.

This study measured the online video module as effective in improving faculty's knowledge of the integration and assessment of PPCP within the school's curriculum. The module provided faculty with a detailed overview of courses and activities within the courses that either introduced, reinforced, or promoted mastery of PPCP, along with a description of the type of assessment utilized. This was helpful in identifying gaps in curricular coverage and assessment. Additionally, the module encouraged faculty dialogue with others currently implementing PPCP teaching to identify opportunities and potential techniques to add PPCP teaching into their own content, courses, and practice.

The online video module was an innovative, minimal resource allocation tool to enhance faculty professional development. Faculty were allowed to watch the video at their convenience and were exposed to the content without the need for a faceto-face meeting. The tool represents enduring content that is maintained virtually and is continually available to faculty as a resource. Using this type of technology would also benefit distance-learning sites. Additionally, the tool can be used to educate other stakeholders - such as external preceptors, pharmacy students, and school staff. Utilization of the module helps to promote the use of consistent terminology and represents an avenue for ongoing development on PPCP and advancements in the process.

This study has a few limitations. The survey instrument was not piloted in a test group before the study. The pre- and postquestionnaires were not matched to identify individual improvement. Further studies may be needed to evaluate changes in individual faculty perceptions and education. The small same size may be a limitation; however, most colleges of pharmacy employed an average of 47 full-time faculty in $2016 .^{11}$ Lastly, the investigators did not track actual time the participants took to watch the video to ensure that participants did not "fast forward" the module without viewing the entire content. However, the investigators attempted to limit this action by embedding the postassessment link within the video.

This manuscript describes an effective approach to faculty development addressing PPCP. The tool utilized in the study did not require much resource or time allocation and promoted improved faculty perceptions and knowledge of PPCP. Additionally, the module improved faculty awareness of the level of curricular integration and assessment of the process within the school.

\section{Next Steps}

The PPCP-FG continues to utilize the video module for the educational needs of stakeholders, students, and new faculty. The PPCP video module was revised to a 15-minute duration, with an enhanced focus on content related to PPCP model implementation using case illustrations, and was shared with the School's preceptors and students. Currently, the PPCP-FG is analyzing outcomes of these educational interventions.

Beginning in the 2017-2018 academic year, the video module was added as a requirement for new faculty orientation. Currently, the School's experiential department is evaluating the use of this video module for continued preceptor development. On a national level, the video module was shared within the American Association of Colleges of Pharmacy's (AACP) PPCP catalyst group's on-line community. In general, development of a similar faculty development module is feasible for implementation in other Schools of Pharmacy.

Acknowledgements: The authors thank the Joint Commission of Pharmacy Practitioners (JCPP) for permissions granted to utilize the Pharmacists' Patient Care Process (PPCP) images and the JCPP-developed slides in this educational intervention.

Disclosures: The authors presented the information at the 2017 AACP Annual Meeting, Nashville, TN as an interactive peer-reviewed poster. 


\section{References}

1. Hepler CD, Strand LM. Opportunities and responsibilities in pharmaceutical care. Am J Hosp Pharm. 1990;47(3):533543.

2. American Society of Hospital Pharmacists. ASHP statement on pharmaceutical care. Am J Hosp Pharm. 1993; 50:17201723.

3. Medication therapy management in pharmacy practice. Core elements of an MTM service model. Version 2.0. American Pharmacists Association and National Association of Chain Drug Stores Foundation. March 2008. https://www.pharmacist.com/sites/default/files/files/core _elements_of_an_mtm_practice.pdf. Accessed March 26, 2018.

4. Patient-Centered Primary Care Collaborative. The Patient Centered Medical Home: Integrating Comprehensive Medication Management to Optimize Patient Outcomes Resource Guide. 2nd ed. 2012.

https://www.pcpcc.org/sites/default/files/media/medman agement.pdf. Accessed March 26, 2018.

5. Harris IM, Phillips B, Boyce E, et al. Clinical pharmacy should adopt a consistent process of direct patient care. Pharmacotherapy. 2014;34(8):e133-e148. doi: 10.1002/phar.1459

6. Joint Commission of Pharmacy Practitioners. Pharmacists' Patient Care Process. 2014. https://jcpp.net/wpcontent/uploads/2016/03/PatientCareProcess-withsupporting-organizations.pdf. Accessed March 26, 2018.

7. Bennett M, Kliethermes MA (Eds). How to Implement the Pharmacists' Patient Care Process. Washington DC: American Pharmacists Association; 2015.

8. Accreditation Council for Pharmacy Education. Accreditation standards and key elements for the professional program in pharmacy leading to the doctor of pharmacy degree. Standards 2016. https://www.acpeaccredit.org/pdf/Standards2016FINAL.pdf. Accessed March 26, 2018.

9. American Association of Colleges of Pharmacy Council of Faculties. Pharmacists' Patient Care Process SelfAssessment Tool, Appendix 3. Tampa, FL American Association of Colleges of Pharmacy; 2016.

10. Hughes PJ, Waldrop B, Chang J. Student perceptions of and performance in a blended foundational drug information course. Curr Pharm Teach Learn. 2016; 8:35963. doi: 10.1016/j.cptl.2016.02.013

11. Academic Pharmacy's Vital Statistics. Institutions and Programs. American Association of Colleges of Pharmacy. Available at: https://www.aacp.org/article/academicpharmacys-vital-statistics. Accessed March 26, 2018. 
Table 1. Original Video Outline and Timings

1. Timeline of development of the PPCP model [3 minutes]

a. History of the Joint Commission of Pharmacy Practitioners (JCPP)

b. JCPP vision and strategic plan which led to development of PPCP

c. PPCP teaching incorporated into ACPE standards

d. National organizational support for PPCP

2. PPCP overview [14 minutes]

a. Core components
i. Collaboration
ii. Documentation of care
iii. Communication of care

b. Five elements and practice examples

c. Case example of using PPCP

3. Curricular (Didactic \& Experiential) integration of PPCP based on the Self-Assessment Tool [5 minutes]

a. Teaching

b. Assessment 
Table 2. Faculty Perceptions of PPCP Before and After an Online Video Module

\begin{tabular}{|c|c|c|c|c|c|c|c|}
\hline Survey Questions & Groups & $\begin{array}{l}\text { Strongly } \\
\text { Agree (\%) }\end{array}$ & $\begin{array}{l}\text { Agree } \\
\text { (\%) }\end{array}$ & $\begin{array}{l}\text { Neutral } \\
(\%)\end{array}$ & $\begin{array}{l}\text { Disagree } \\
(\%)\end{array}$ & $\begin{array}{l}\text { Strongly } \\
\text { Disagree } \\
(\%)\end{array}$ & $\begin{array}{c}p \\
\text { value }\end{array}$ \\
\hline \multirow{2}{*}{$\begin{array}{l}\text { I feel that I am very knowledgeable of the } \\
\text { Pharmacists' Patient Care Process (PPCP). }\end{array}$} & $\begin{array}{l}\text { Pre- } \\
\text { test }\end{array}$ & 40 & 40 & 4 & 13 & 3 & \\
\hline & $\begin{array}{l}\text { Post- } \\
\text { test }\end{array}$ & 32 & 68 & 0 & 0 & 0 & 0.01 \\
\hline \multirow{2}{*}{$\begin{array}{l}\text { I feel that individuals in my profession are very } \\
\text { knowledgeable of PPCP. }\end{array}$} & $\begin{array}{l}\text { Pre- } \\
\text { test }\end{array}$ & 7 & 30 & 20 & 33 & 10 & \\
\hline & $\begin{array}{l}\text { Post- } \\
\text { test }\end{array}$ & 10 & 42 & 26 & 19 & 3 & 0.12 \\
\hline \multirow{2}{*}{ I feel students should be educated on the PPCP. } & $\begin{array}{l}\text { Pre- } \\
\text { test }\end{array}$ & 63 & 30 & 4 & 0 & 3 & \\
\hline & $\begin{array}{l}\text { Post- } \\
\text { test }\end{array}$ & 81 & 16 & 0 & 0 & 3 & 0.14 \\
\hline \multirow{2}{*}{$\begin{array}{l}\text { I feel that implementation of the PPCP into } \\
\text { pharmacy practice would improve patient health } \\
\text { outcomes. }\end{array}$} & $\begin{array}{l}\text { Pre- } \\
\text { test }\end{array}$ & 37 & 40 & 20 & 0 & 3 & \\
\hline & $\begin{array}{l}\text { Post- } \\
\text { test }\end{array}$ & 71 & 26 & 0 & 0 & 3 & 0.004 \\
\hline \multirow{2}{*}{$\begin{array}{l}\text { I feel that implementation of the PPCP into } \\
\text { pharmacy practice would prevent more } \\
\text { medication errors. }\end{array}$} & $\begin{array}{l}\text { Pre- } \\
\text { test }\end{array}$ & 23 & 47 & 20 & 7 & 3 & \\
\hline & $\begin{array}{l}\text { Post- } \\
\text { test }\end{array}$ & 58 & 36 & 3 & 0 & 3 & 0.002 \\
\hline
\end{tabular}


Figure 1: Percentage of Faculty that Accurately Identified Written Statements with the Correct Component of PPCP $\left({ }^{*} p<.001\right)$

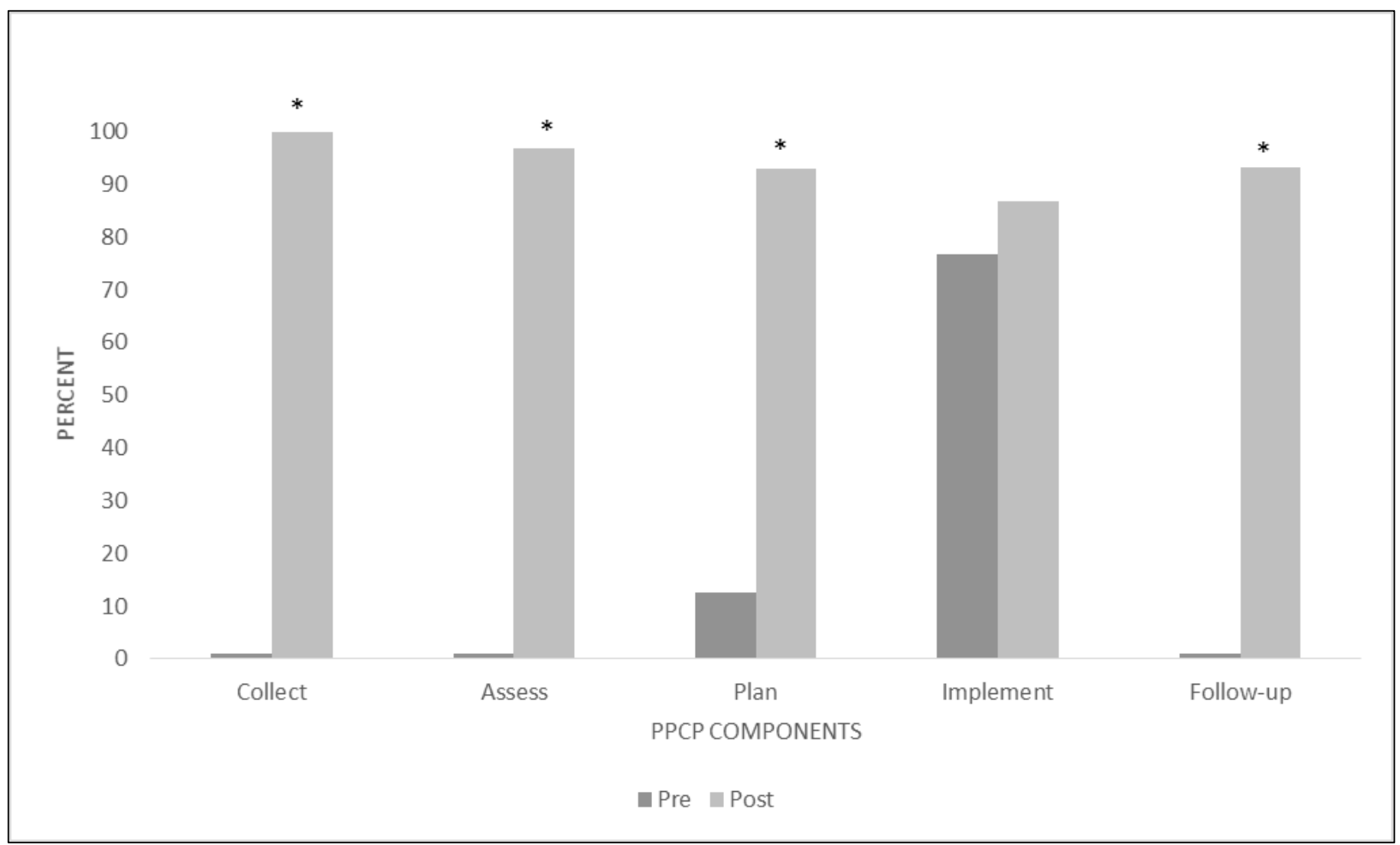

